\title{
Minimally invasive surgery for gastric cancer
}

\author{
Ali Güner ${ }^{1,2,3}$, Woo Jin Hyung ${ }^{1,3,4}$
}

ABSTRACT

'Department of Surgery, Yonsei University College of Medicine, Seoul, South Korea

${ }^{2}$ Department of General Surgery, Trabzon Kanuni Training and Research Hospital, Trabzon, Turkey

${ }^{3}$ Yonsei University Health System, Robot and MIS Center, Seoul, South Korea

${ }^{4}$ Yonsei University Health System, Gastric Cancer Clinic, Seoul, South Korea

\section{Address for Correspondence Ali Güner, MD}

Department of General Surgery, Trabzon Kanuni Training and Research Hospital, Trabzon, Turkey Phone: +90 5066617119 e-mail: draliguner@yahoo.com

Received: 17.12.2013 Accepted: 09.01.2014

\section{(c) Copyright 2014} by Turkish Surgical Association Available online at www.ulusalcerrahidergisiorg
The interest in minimally invasive surgery (MIS) has rapidly increased in recent decades and surgeons have adopted minimally invasive techniques due to its reduced invasiveness and numerous advantages for patients. With increased surgical experience and newly developed surgical instruments, MIS has become the preferred approach not only for benign disease but also for oncologic surgery. Recently, robotic systems have been developed to overcome difficulties of standard laparoscopic instruments during complex procedures. Its advantages including threedimensional images, tremor filtering, motion scaling, articulated instruments, and stable retraction have created the opportunity to use robotic technology in many procedures including cancer surgery. Gastric cancer is one of the most common causes of cancer-related deaths worldwide. While its overall incidence has decreased worldwide, the proportion of early gastric cancer has increased mainly in eastern countries following mass screening programs. The shift in the paradigm of gastric cancer treatment is toward less invasive approaches in order to improve the patient's quality of life while adhering to oncological principles. In this review, we aimed to summarize the operative strategy and current literature in laparoscopic and robotic surgery for gastric cancer.

Key Words: Gastric cancer, gastrectomy, minimally invasive surgery, laparoscopy, robotics

\section{INTRODUCTION}

Following the first report of laparoscopic cholecystectomy, the interest in minimally invasive surgery (MIS) has rapidly increased, and this approach has been introduced for various surgical procedures. When compared to open surgery, MIS is known by its several advantages such as reduced invasiveness, less pain, rapid recovery and improved cosmetic outcomes. However, its safety and feasibility for oncological surgery is still under debate (1). Nevertheless, with the increasing experience of surgeons and the adaptation of newly developed surgical instruments such as endoscopic stapling or sealing devices, MIS has become the widely preferred approach even for cancer surgery that consists of more complicated procedures compared to surgeries of benign diseases. In the last decade, the technical disadvantages that are faced during conventional laparoscopy have been reduced to minimum with the introduction of robotic technology. Its advantages like three-dimensional images, tremor filtering, motion scaling, articulated instruments, and stable retraction have created the opportunity to use robotic technology in many surgical specialties including cancer surgery (2).

Gastric cancer is still a major health problem and one of the leading causes of cancer-related death despite its decreasing incidence worldwide. In some eastern countries, following the advances in diagnostic instruments and increased use of mass-screening programs, the incidence of early gastric cancer (EGC) has risen to $60 \%$ (3). Following the favorable outcomes that were reported for EGC, surgeons became interested in improving the quality of life, in addition to surgical curability. Following Kitano's first report of laparoscopic-assisted distal gastrectomy in gastric cancer in 1994, laparoscopic gastrectomy (LG) has been accepted as a feasible alternative to open surgery in EGC (4). With increasing surgical experience, laparoscopic surgery has also come into use for total gastrectomy, extended lymph node dissection and advanced gastric cancer (AGC) (5). In this process, robotic gastrectomy (RG) has also taken its place in practice, and experienced centers have started using robotic system for radical gastrectomy (6). Despite the presence of minimally invasive (MI) procedures such as endoscopic mucosal resection, endoscopic submucosal dissection, laparoscopic wedge/segmental resection with sentinel node navigation for early-stage lesions, this study will evaluate the current status of LG and RG.

\section{Indications for Minimally Invasive Gastrectomy}

Previous edition of Japanese gastric cancer treatment guidelines recommended using laparoscopic surgery in clinical stage IA (cT1N0) and stage IB (cT1N1, cT2N0) gastric tumors for investigational purposes (7). In the latest version of the Japanese gastric cancer treatment guidelines, which was published in 2011, LG was still assigned as an investigational treatment due to a lack of prospective studies with suffici- 
ent sample size (8). According to the current literature, MIS is commonly used for patients with stage IA, stage IB, and stage IIA diseases (9). Generally, patients with obvious preoperative findings of serosa-positive cancers and distant metastases are not indicated for MI gastrectomy. The indications for RG are similar to those of LG. Specific contraindications of MI gastrectomy include patients with severe pulmonary or cardiac disease who will not tolerate pneumoperitoneum for a long period.

\section{Operative strategy}

Patient positioning and port placement: The patient is placed in a supine position and $15^{\circ}$ reverse Trendelenburg position is maintained. The RG procedure follows the same technical steps as those of LG; however, port placements differ between LG and RG. Generally, port placements are similar for total and subtotal gastrectomy. In some cases, minor adjustments are made depending on patient body habitus.

For LG, an infra-umbilical 10-mm camera port is placed. After a pneumoperitoneum of $12 \mathrm{mmHg}$ is achieved, ports are placed at the right upper quadrant, right lateral side, left upper quadrant, and left lateral side of the abdomen under direct visualization (Figure 1A). The surgeon and scope operator are located on the right side of the patient and an assistant is on the left side. For RG, a $12 \mathrm{~mm}$ camera port is used just below the umbilicus. Three $8-\mathrm{mm}$ robotic ports and one $12 \mathrm{~mm}$ assistant port are placed under direct visualization (Figure 1B). First robotic arm is placed to the left side just below the costal angle. Second and third arms are placed on the right side. Assistant port is placed between the camera port and first robotic arm. Then, patient cart is rolled and robotic arms are docked. Generally, the first arm is used for curved bipolar Maryland forceps. Ultrasonic shears and Cadiere forceps are hold by second and third arms, respectively.

Liver retraction: During MI gastrectomy procedures, retracting the liver is essential for clear visualization of the anterior surface of the hepatogastric and hepatoduodenal ligament. Various techniques have been defined so far. Techniques, which use liver retractors, require an additional $5 \mathrm{~mm}$ port. However, the technique of liver suspension using suture gauze is an effective and safe method, which does not require additional port and allows one port to be free (Figure 2A) (10).

A
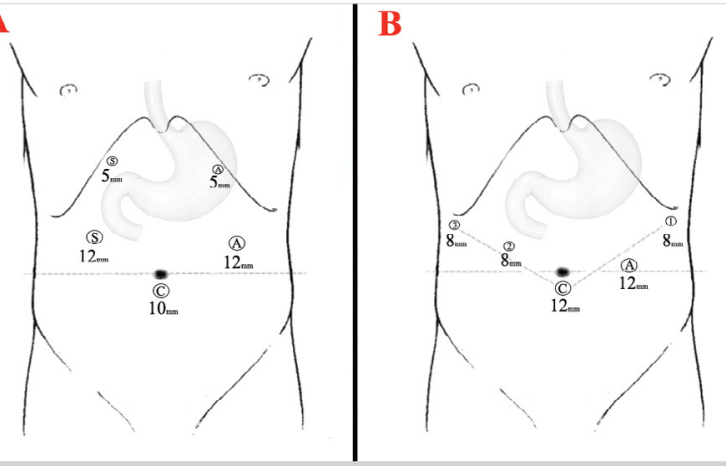

Figure 1. Port placements for laparoscopic (A); and robotic gastrectomy (B).

S: surgeon; A: assistant; C: camera
Intraoperative tumor localization: In order to determine safe resection margin during $\mathrm{Ml}$ gastrectomy, tumor localization is essential. Dye injection, intraoperative endoscopy, intraoperative ultrasound or endoscopic clipping and then abdominal plain radiograph can achieve this. The last one provides accurate localization without the need for special equipment or time-consuming procedures. Two or three metallic endoclips are applied preoperatively. During the initial part of the operation, metallic vessel clips are applied along the greater and lesser curvatures of the stomach. Then, an intraoperative portable radiograph is taken to identify the location of endoclips and external vessel clips. The absolute distance between the endoclips and vessel clips is measured to determine the safe resection margin (Figure $2 \mathrm{~B}$ ) (11).

Extent of omentectomy: According to the Japanese gastric cancer treatment guidelines, the omentum more than $3 \mathrm{~cm}$ away from the gastroepiploic vessels may be preserved for T1 and T2 tumors. Total omentectomy is recommended for T3 or deeper tumors (8).

Extent of lymphadenectomy: According to the Japanese gastric cancer treatment guidelines, extent of lymphadenectomy is decided based on clinical stage of the tumor and type of gastrectomy indicated. D1+ lymphadenectomy is indicated for cT1N0 tumors and D2 is indicated for CN+ or CT2-T4 tumors. For distal gastrectomy, D1+ lymphadenectomy includes the lymph nodes numbered as 1, 3, 4sb, 4d, 5, 6, 7, 8a and 9. D2 lymphadenectomy includes no $11 \mathrm{p}$ and $12 \mathrm{a}$ in addition to D1+ lymphadenectomy. For total gastrectomy, D1+ lymphadenectomy includes no 1-7, 8a, 9, 11p and D2 lymphadenectomy includes no $10,11 \mathrm{~d}, 12 \mathrm{a}$ in addition to D1+ lymphadenectomy (8).

Left side dissection: The first step in Ml gastrectomy is partial omentectomy in most cases. The procedure begins by dividing the omentum from the mid-transverse colon about 4-5 $\mathrm{cm}$ away from the gastroepiploic vessels by using harmonic shears. The left gastroepiploic vessels are divided at their root. Lymph nodes $4 \mathrm{sb}$ and $4 \mathrm{~d}$ are taken for distal gastrectomy and greater curvature is cleared for transection and anastomosis line. For total gastrectomy, short gastric vessels are divided additionally and lymph nodes 4 sa and 2 are included in the specimen. During D2 lymphadenectomy, lymph nodes $11 \mathrm{~d}$ and 10 are also dissected for total gastrectomy while preserving the spleen and splenic vessels.

Right side and infrapyloric dissection: The procedure continues to the right side of the omentum by dissecting along the middle colic vessels while exposing the head of the pancreas. The gastrocolic trunk is identified and right gastroepiploic vein is divided while preserving the venous drainage of pancreas head. For dissection of lymph node 6, the soft tissues above the anterior superior pancreaticoduodenal vein laterally and the middle colic vein medially is retrieved (Figure 3A). After dissection of soft tissues around pancreas head, right gastroepiploic artery is divided. Dissection goes up to the bifurcation of the posterior pancreatic duodenal artery and the gastroduodenal artery to mobilize 


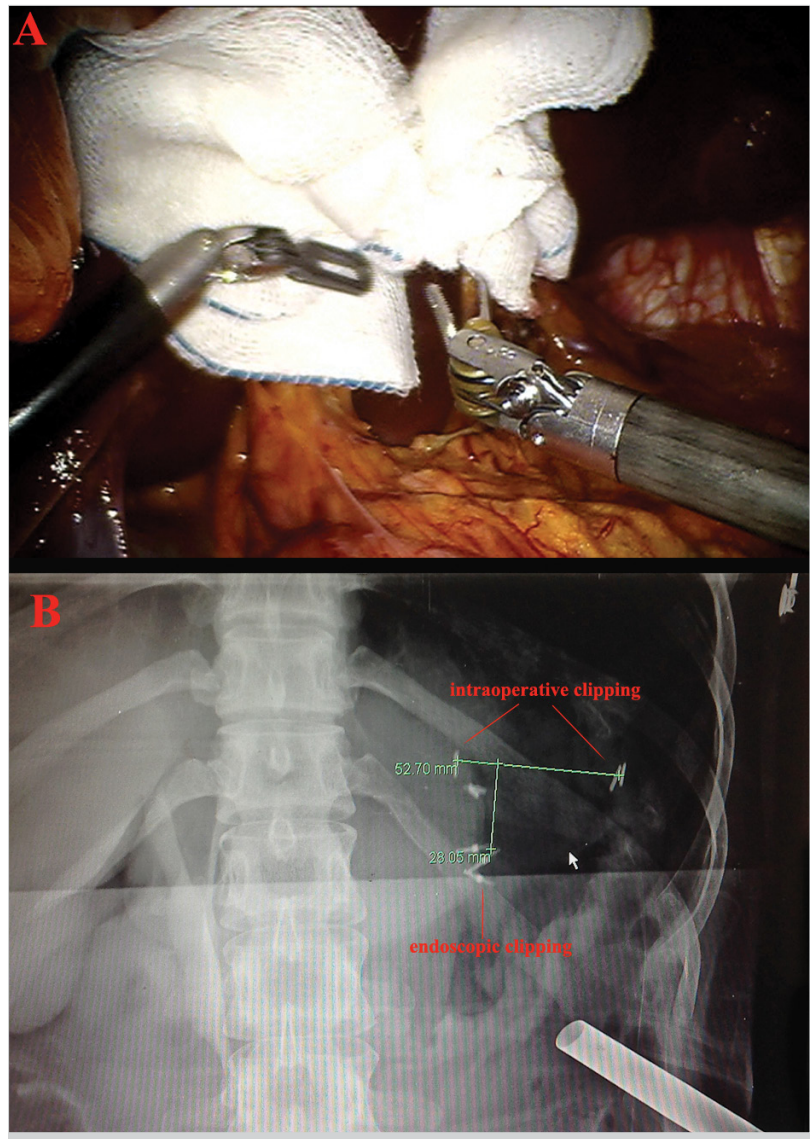

Figure 2. Intraoperative view of hepatogastric and hepatoduodenal ligament after liver retraction by using suture gauze method $(A)$; and view of intraoperative portable radiograph after applying clips to the lesser and greater curvature (B). Distance between the preoperatively applied endoscopic clips and intraoperatively applied vessel clips is measured to determine resection margin safety.

the duodenum from the pancreas. A gauze is placed on the top of the pancreas below the duodenum to help suprapyloric dissection.

Suprapyloric dissection and duodenum division: Supraduodenal vessels are divided by using harmonic shears. Dissection continues along the gastroduodenal artery to expose the proper and common hepatic artery. Duodenum is transected by using linear endoscopic stapler.

Suprapancreatic dissection and lesser curvature mobilization: After duodenal division the right gastric vessels are divided. Soft tissues around the common hepatic artery are dissected (lymph nodes 5 and 8) until the left gastric vein is identified. For D2 dissection, soft tissues (lymph node 12a) around the proper hepatic artery and medial side of the portal vein should be included in the specimen (Figure 3B). After left gastric vein division, soft tissues around left gastric artery are dissected (lymph nodes 7 and 9). For lymph node 11 p dissection, pancreas should be moved down gently by using gauze. Soft tissues along superior border of the pancreas and the proximal part of the splenic artery are dissected (Figure $3 \mathrm{C}$ ). Retroperitoneal attachment of the stomach is detached, completing the removal of the perigastric lymph nodes 1 and 3 .
Reconstruction: After gastric resection, reconstruction is performed by either the intracorporeal or the extracorporeal method. All reconstruction steps can be completed totally laparoscopic or robotic by using endoscopic linear staplers. After distal gastrectomy, Billroth-I gastroduodenostomy, Billroth-II gastrojejunostomy, or Roux-en-Y gastrojejunostomy, and after total gastrectomy Roux-en-Y esophagojejunostomy are the options that can be chosen depending on surgeon preference (Figure 3D).

\section{Existing Evidence for Minimally Invasive Gastrectomy}

\section{Laparoscopic gastrectomy versus Open gastrectomy}

To date, eight randomized controlled trials (RCT) that compared LG and open gastrectomy (OG) have been published (12-19). In all of these studies except one, patients who underwent laparoscopic distal gastrectomy (LDG) were compared to those who underwent open distal gastrectomy (ODG), and patients who underwent total gastrectomy were excluded. $\mathrm{Pa}$ tients with AGC were included only in two studies, while the remaining six studies only included patients with EGC.

The short-term outcomes of six RCTs that were published for EGC are presented in Table 1. In the meta-analysis of these six studies, lower postoperative morbidity (risk ratio $=0.61$, $p=0.01$ ), less blood loss (mean difference $[M D]=108.33$ $\mathrm{mL}, \mathrm{p}=0.001)$, longer operation time $(M D=86.6$ minutes, $\mathrm{p}<0.00001)$, and decreased number of retrieved lymph nodes ( $M D=4.88, p<0.00001$ ) were found in LDG group (323 patients) compared with the ODG group (306 patients) (20). Long-term outcomes have been published for only one of these studies so far. In the report of the Collaborative Action for Gastric Cancer group (COACT 0301), there was no difference in diseasefree survival (5-year disease-free survival: $98.8 \%$ vs. $97.6 \%$, respectively) and overall survival (5-year overall survival: 97.6 vs. $96.3 \%$, respectively) between the LG and OG groups ( $p=0.514$ vs. $p=0.721$, respectively) (21). This study also evaluated the short-term and long-term quality of life in patients after gastrectomy. While LDG did not have any advantage over ODG in terms of long-term complications and long-term quality of life, LDG showed better outcomes with respect to mild short-term complications and short-term quality of life.

The multi-institutional KLASS-01 study by the Korea Laparoscopic Gastrointestinal Surgery Study Group (KLASS), which began to recruit patients in 2006, is a phase III study that compares LDG and ODG in distal EGC. The primary outcome of the study was overall survival, and 1485 patients were enrolled in the study. As secondary outcomes, the investigators planned to compare progression-free survival, morbidity/mortality, quality of life, immune/inflammatory response, and cost. An interim report that evaluates the safety of the trial was published in 2010, and there was no significant difference on morbidity and mortality between LDG and ODG groups (18). Patient recruitment was completed in 2012 and long-term outcomes are awaited. After the phase II JCOG0703 study, which was carried out by the Japan Clinical Oncology Group (JCOG) in Japan, the safety and feasibility of LDG were demonstrated, and then the phase III JCOG0912 study was initiated (22). The outcomes of 


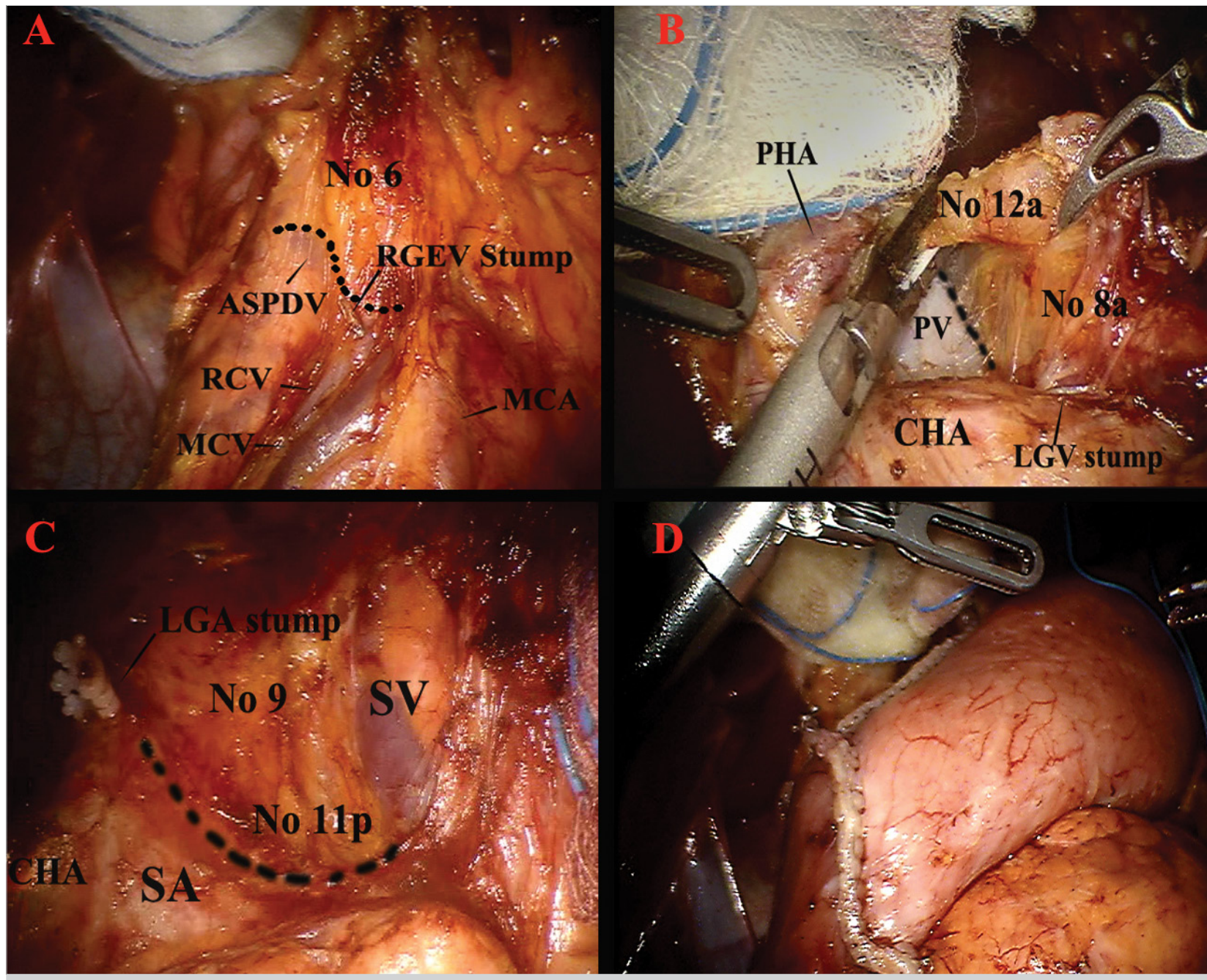

Figure 3. Details of anatomical structures during robotic gastrectomy. Infrapyloric lymph node dissection for no 6 lymph node station (A); lymph node dissection around the proper hepatic artery and the common hepatic artery for no 8a-12a lymph nodes (B); lymph node dissection around the proximal part of the splenic artery and splenic vein for no $11 \mathrm{p} \mathrm{lymph} \mathrm{node} \mathrm{(C);}$ intracorporeal reconstruction with delta-shaped Billroth-I gastroduodenostomy after distal gastrectomy (D).

ASPDV: anterior superior pancreaticoduodenal vein; RGEV: right gastroepiploic vein; RCV: right colic vein (accessory); MCV: middle colic vein; MCA: middle colic artery; PHA: proper hepatic artery; PV: portal vein; CHA: common hepatic artery; LGV: left gastric vein; LGA: left gastric artery; SV: splenic vein; SA: splenic artery

these two eastern studies will provide high-level evidence to demonstrate the efficacy of LDG for early-stage distal cancers.

To date, only two RCTs that evaluated LG for AGC have been published $(16,19)$. Both studies concluded that LG with D2 lymphadenectomy was a feasible and oncologically safe method for AGC. In the meta-analysis of two RCTs and 13 retrospective series, the LG group had longer operation time (MD: 48.67 minutes, $\mathrm{p}<0.001$ ), less blood loss (MD: $139.01 \mathrm{~mL}$, $p<0.001$ ), earlier time to first flatus (MD: 0.79 days, $p<0.001$ ), shorter hospital stay (MD: 3.11 days, $\mathrm{p}<0.001$ ), and lower complications (risk ratio $=0.74, p=0.003$ ) when compared with the OG group (23). In addition to short-term outcomes, this meta-analysis also included two critical oncological outcomes such as long-term survival and recurrence. Cancer recurrence and the long-term survival in LG were similar to those in OG. Moreover, the analysis also evaluated cancer cell dissemination caused by pneumoperitoneum, which is another concern of laparoscopic oncologic surgery. Although quite rare, port site recurrence was seen in two of the included studies (one patient in each of two studies, on postoperative $10^{\text {th }}$ and $13^{\text {th }}$ month). On the other hand, in one of the included studies, wound metastases were detected in two patients (one in the incision, one in the drain orifice) in the OG group, and authors stated that port site metastasis was not specific for LG (24).

Regarding AGC, it is difficult to conduct a high-quality study due to the technical difficulties of lymph node dissection during $L G$ and the technical heterogeneity among the surgeons. To overcome this concern, KLASS-02-QC study was carried out prior to the KLASS-02-RCT study (Prospective Multicenter Randomized Controlled Clinical Trial for Comparison between Laparoscopic and Open Subtotal Gastrectomy with D2 Lymph Node Dissection for Locally Advanced Gastric Cancer) in order to standardize D2 lymphadenectomy. The surgeons who would participate in the RCT were selected after this quality-control study. KLASS-02-RCT that was started in 2011 aimed to enroll 1050 patients and continues to recruit patients. The results 
Table 1. Results of randomized controlled trials comparing laparoscopic gastrectomy and open gastrectomy

\begin{tabular}{|c|c|c|c|c|c|c|c|c|c|c|c|c|c|c|c|}
\hline Author & $\begin{array}{l}\text { Country } \\
\text { Year }\end{array}$ & $\begin{array}{c}\text { Type of } \\
\text { gastrectomy }\end{array}$ & Indication & $\begin{array}{c}\text { No. of } \\
\text { patients }\end{array}$ & $\begin{array}{l}\text { Extent } \\
\text { of LND }\end{array}$ & $\begin{array}{l}\text { Operative } \\
\text { time (min) }\end{array}$ & $\begin{array}{c}\text { Blood } \\
\text { loss }(\mathrm{mL})\end{array}$ & $\begin{array}{l}\text { Conversion } \\
\text { to open (\%) }\end{array}$ & $\begin{array}{l}\text { No. of } \\
\text { retrieved LN }\end{array}$ & $\begin{array}{c}\text { Oral } \\
\text { intake (day) }\end{array}$ & $\begin{array}{l}\text { Hospital } \\
\text { stay (day) }\end{array}$ & $\begin{array}{l}\text { Morbidity } \\
(\%)\end{array}$ & $\begin{array}{l}\text { Mortality } \\
\text { (\%) }\end{array}$ & $\begin{array}{l}\text { DFS } \\
\text { (\%) }\end{array}$ & $\begin{array}{l}\text { OS } \\
\text { (\%) }\end{array}$ \\
\hline \multirow[t]{2}{*}{ Kitano et al. (12) } & Japan & LADG & EGC & 14 & $\mathrm{D} 1+\mathrm{a}$ & $227^{*}$ & $117^{*}$ & 0 & 20 & 5 & 18 & 14 & 0 & NR & NR \\
\hline & 2002 & ODG & & 14 & $\mathrm{D} 1+\mathrm{a}$ & $171^{*}$ & $258^{*}$ & & 25 & 5 & 16 & 29 & 0 & NR & NR \\
\hline \multirow[t]{2}{*}{ Fujii et al. (13) } & Japan & LADG & EGC & 10 & $\mathrm{D} 1+\mathrm{a}$ & $226^{*}$ & 134 & 0 & NR & NR & NR & 20 & 0 & NR & NR \\
\hline & 2003 & ODG & & 10 & $\mathrm{D} 1+\mathrm{a}$ & $180^{*}$ & 206 & & NR & NR & NR & 20 & 0 & NR & NR \\
\hline \multirow[t]{2}{*}{ Hayashi et al. (14) } & Japan & LADG & EGC & 14 & $\mathrm{D} 1+\mathrm{a}$ & $378^{*}$ & 327 & 0 & 28 & $4^{*}$ & $12^{*}$ & $29^{* *}$ & $1^{b}$ & NR & NR \\
\hline & 2005 & ODG & & 14 & $\mathrm{D} 1+\mathrm{a}$ & $235^{*}$ & 489 & & 27 & $5^{*}$ & $18^{*}$ & $57^{* *}$ & 0 & NR & NR \\
\hline \multirow[t]{2}{*}{ Lee et al. (15) } & Korea & LADG & EGC & 24 & D2 & $319^{*}$ & 336 & 0 & 32 & 5 & 11 & $13^{*}$ & 0 & NR & NR \\
\hline & 2005 & ODG & & 23 & D2 & $190^{*}$ & 294 & & 38 & 6 & 17 & $43^{*}$ & 0 & NR & NR \\
\hline \multirow[t]{2}{*}{ Huscher et al. (16) } & Italy & TLDG & $\mathrm{EGC}+\mathrm{AGC}$ & 30 & D1/D2 & 196 & $229^{*}$ & 0 & 30 & $5^{*}$ & $10^{*}$ & 27 & 3 & $57^{c}$ & $59^{c}$ \\
\hline & 2005 & ODG & & 29 & & 168 & $391^{*}$ & & 33 & $7^{*}$ & $15^{*}$ & 28 & 7 & $55^{c}$ & $56^{c}$ \\
\hline \multirow[t]{2}{*}{ Kim et al. $(17,21)$} & Korea & LADG & EGC & 82 & $\mathrm{D} 1+\beta / \mathrm{D} 2$ & $253^{*}$ & $112^{*}$ & 1 & $39^{*}$ & $4^{*}$ & $7^{*}$ & 0 & 0 & $99^{c}$ & $98^{c}$ \\
\hline & 2008 & ODG & & 82 & & $171^{*}$ & $267^{*}$ & & $45^{*}$ & $4^{*}$ & $9^{*}$ & 5 & 0 & $98^{c}$ & $96^{c}$ \\
\hline \multirow[t]{2}{*}{ Kim et al. (18) } & Korea & LADG & EGC & 179 & $\mathrm{D} 1+\beta / \mathrm{D} 2$ & NR & $109^{*}$ & 0 & NR & NR & NR & 12 & 1 & NR & NR \\
\hline & 2010 & ODG & & 161 & & NR & $200^{*}$ & & NR & NR & NR & 15 & 0 & NR & NR \\
\hline \multirow[t]{2}{*}{ Cai et al. (19) } & China & LAGe & $\mathrm{EGC}+\mathrm{AGC}$ & 49 & D2 & $271^{*}$ & 294 & 3 & 23 & 7 & 12 & 12 & 0 & NR & $67^{d}$ \\
\hline & 2011 & OGe & & 47 & & $188^{*}$ & 344 & & 23 & 6 & 11 & 19 & 0 & NR & 54 \\
\hline
\end{tabular}

*: Statistically significant; **:Statistically significance is unknown.

a: According to the Japanese Gastric Cancer Treatment Guidelines-second english edition; b:POD 145, at home; $;$ 5-year survival data d: 3-year survival data; : Includes total, distal or proximal gastrectomy

NR: not reported; LND: lymph node dissection; DFS: disease-free survival; OS: overall survival; LADG: laparoscopic-assisted distal gastrectomy; TLDG: totally laparoscopic distal gastrectomy, ODG: open distal gastrectomy; EGC: early gastric cancer,

AGC: advanced gastric cancer 
Table 2. Results of studies comparing robotic gastrectomy and laparoscopic gastrectomy ( \pm open gastrectomy)

\begin{tabular}{|c|c|c|c|c|c|c|c|c|c|c|c|c|}
\hline Author & $\begin{array}{c}\text { Country } \\
\text { Year }\end{array}$ & $\begin{array}{c}\text { Type of } \\
\text { gastrectomy }\end{array}$ & Indication & $\begin{array}{c}\text { No. of } \\
\text { patients }\end{array}$ & $\begin{array}{l}\text { Extent } \\
\text { of LND }\end{array}$ & $\begin{array}{c}\text { Operative } \\
\text { time (min) }\end{array}$ & $\begin{array}{c}\text { Blood } \\
\text { loss }(\mathrm{mL})\end{array}$ & $\begin{array}{c}\text { Conversion } \\
\text { rate (\%) }\end{array}$ & $\begin{array}{c}\text { No. of } \\
\text { retrieved LN }\end{array}$ & $\begin{array}{l}\text { Hospital } \\
\text { stay (day) }\end{array}$ & $\begin{array}{c}\text { Morbidity } \\
\text { (\%) }\end{array}$ & $\begin{array}{c}\text { Mortality } \\
\text { (\%) }\end{array}$ \\
\hline \multirow[t]{3}{*}{ Kim et al. (39) } & Korea & RADG & EGC & 16 & $\mathrm{D} 1+\beta / \mathrm{D} 2$ & $259^{*}$ & $30^{*}$ & 0 & 41 & $5^{*}$ & 0 & 0 \\
\hline & 2010 & LADG & & 11 & & $203^{*}$ & $45^{*}$ & 0 & 37 & $7^{*}$ & 9 & 0 \\
\hline & & ODG & & 12 & & $126^{*}$ & $79^{*}$ & & 43 & $7^{*}$ & 16 & 0 \\
\hline \multirow[t]{2}{*}{ Pugliese et al. (29) } & Italy & RDG & $\mathrm{EGC}+\mathrm{AGC}$ & 18 & D2 & 344 & 90 & $12^{*}$ & 25 & 10 & 6 & 6 \\
\hline & 2010 & LDG & & 52 & & 235 & 148 & $6^{*}$ & 31 & 10 & 13 & 2 \\
\hline \multirow[t]{2}{*}{ Woo et al. (30) } & Korea & $\mathrm{RAG}^{\mathrm{b}}$ & $\mathrm{EGC}+\mathrm{AGC}$ & 236 & $D 1+\alpha-\beta / D 2$ & $220^{*}$ & $92^{*}$ & 0 & 39 & $8^{*}$ & 11 & $<1$ \\
\hline & 2011 & $\mathrm{LAG}^{\mathrm{b}}$ & & 591 & & $171^{*}$ & $148^{*}$ & 0 & 37 & $7^{*}$ & 14 & $<1$ \\
\hline \multirow[t]{2}{*}{ Eom et al. (31) } & Korea & RADG & $\mathrm{EGC}+\mathrm{AGC}$ & 30 & $D 1+\beta / D 2$ & $229^{*}$ & 153 & 0 & 30 & 8 & 6 & 0 \\
\hline & 2012 & LADG & & 62 & & $189^{*}$ & 88 & 0 & 33 & 8 & 13 & 0 \\
\hline \multirow[t]{2}{*}{ Uyama et al. (32) } & Japan & RDG & $\mathrm{EGC}+\mathrm{AGC}$ & 25 & $D 1+\beta / D 2$ & 361 & $52^{*}$ & 0 & 44 & $12^{*}$ & 11 & 0 \\
\hline & 2012 & LDG & & 225 & & 345 & $81^{*}$ & 0 & 43 & $17^{*}$ & 17 & 0 \\
\hline \multirow[t]{2}{*}{ Yoon et al. (33) } & Korea & RATG & EGC & 36 & $D 1+\alpha-\beta / D 2$ & $306^{*}$ & NR & NR & 43 & 9 & 17 & 0 \\
\hline & 2012 & LATG & & 65 & & $210^{*}$ & NR & NR & 39 & 10 & 15 & 0 \\
\hline \multirow[t]{2}{*}{ Kang et al. (34) } & Korea & RADG & EGC & 100 & $\mathrm{D} 1+\beta / \mathrm{D} 2$ & $202^{*}$ & $93^{*}$ & 0 & NR & $10^{*}$ & 14 & 0 \\
\hline & 2012 & LADG & & 282 & & $173^{*}$ & $173^{*}$ & NR & NR & $8^{*}$ & 10 & 0 \\
\hline \multirow[t]{2}{*}{ Park et al. (35) } & Korea & RADG & EGC & 30 & $D 1+\beta$ & $218^{*}$ & 75 & 0 & 34 & 7 & 17 & 0 \\
\hline & 2012 & LADG & & 120 & & $140^{*}$ & 60 & 0 & 35 & 7 & 8 & 0 \\
\hline \multirow[t]{3}{*}{ Huang et al. (40) } & Taiwan & RAG & EGC & 39 & $D 1+a-\beta / D 2$ & $430^{*}$ & $50^{*}$ & NR & $32^{*}$ & $7^{*}$ & 15 & 3 \\
\hline & 2012 & LAG & & 64 & & $350^{*}$ & $100^{*}$ & NR & $26^{*}$ & $11^{*}$ & 16 & 2 \\
\hline & & OG & & 586 & & $320^{*}$ & $400^{*}$ & & $34^{*}$ & $12^{*}$ & 15 & 1 \\
\hline \multirow[t]{2}{*}{ Hyun et al. (36) } & Korea & RAG & EGC & 38 & $D 1+\alpha-\beta / D 2$ & 234 & 131 & 0 & 33 & 11 & 47 & 0 \\
\hline & 2013 & LAG & & 83 & & 220 & 130 & 0 & 33 & 12 & 39 & 0 \\
\hline \multirow[t]{2}{*}{ Noshiro et al. (37) } & Japan & RDG & EGC+AGC & 21 & $D 1+\beta / D 2$ & $439^{*}$ & 96 & $5^{* *}$, & 44 & $8^{*}$ & 10 & 0 \\
\hline & 2013 & LDG & & 160 & & $315^{*}$ & 115 & $0^{* *}$ & 40 & $13^{*}$ & 10 & 0 \\
\hline
\end{tabular}

*: Statistically significant; **:Statistically significance is unknown.

a: According to the Japanese Gastric Cancer Treatment Guidelines-second English edition; ${ }^{b}:$ Includes total, subtotal, and completion total gastrectomy; $\mathrm{c}^{\mathrm{c}}$ conversion to laparoscopic total gastrectomy

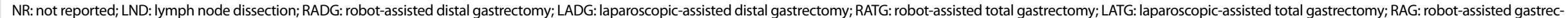

tomy; LAG: laparoscopic-assisted gastrectomy; OG: open gastrectomy; RDG: robotic distal gastrectomy, LDG: laparoscopic distal gastrectomy; ODG: open distal gastrectomy; EGC: early gastric cancer; AGC: advanced gastric cancer 
of this phase III study will provide high-level evidence to demonstrate the efficacy of LDG for patients with AGC. Another prospective RCT for AGC is the JLSSG0901 study, which was planned by the Japanese Laparoscopic Surgery Study Group (JLSSG). This study, which was planned as a phase II (morbidity) and phase III (relapse free-survival) study, continues recruiting patients, too.

Despite the increasing popularity of LDG in distal tumors and the increasing evidence on LDG, the number of studies on laparoscopic total gastrectomy (LTG) is limited. In addition to the lower incidence of proximal gastric cancer in Asian countries, LTG is only performed by limited numbers of surgeons due to technical difficulties in lymphadenectomy around paracardial area or splenic hilum (with/without splenectomy), and difficulties in the reconstruction phase after resection (esophagojejunostomy). All of the studies that have been conducted thus far consisted of nonrandomized cohorts or case-control series. The meta-analysis of nine studies reported that LTG requires longer operation times, but it also has certain advantages including less pain, fewer complications, and rapid recovery when compared to open total gastrectomy (OTG) (25). The learning curve effect was also evaluated in the same study. In LTG group, shorter operation times and less blood loss were observed for operations that were performed by surgeons who had an experience of more than 40 LTG cases. Between the LTG and OTG groups, there was no significant difference in disease-specific survival and overall survival rates, which were reported only in three studies. The KLASS-03 trial, which has been initiated recently, is a prospective study that aims to evaluate the feasibility of LTG for patients with EGC. In the absence of randomized studies, reaching a decision on the safety and efficacy of LTG seems quite difficult.

\section{Robotic gastrectomy versus Open gastrectomy}

Following the rapid spread of the LG, RG has also been placed in the era of MIS to overcome the technical difficulties of laparoscopy. The first large patient series regarding RG was published in 2009. In the 100-patient series that included both robotic total gastrectomy (RTG [n=33]) and robotic distal gastrectomy (RDG $[n=67]$ ) patients, the mean operation time was 231 minutes (initial time: 13 minutes, docking time: 5 minutes, robot time: 150 minutes, assisted time: 63 minutes) (26). In all published series, RG was reported to be a safe and effective alternative. On the other hand, concerns regarding RG include its high cost, longer operation time and lack of data with regard to oncological outcomes.

With increasing use of RG, nonrandomized studies that compared RG and conventional methods are being conducted. In the first study that compared RG and OG, the incidence of perioperative morbidity was higher in the RG group ( $24 \%$ vs. $13 \%)$, while the incidence of postoperative mortality was higher in the OG group (4\% vs. $9 \%$ ) (27). There was no significant difference in operation time at the end of the learning curve. The efficacy of RG (with D2 lymphadenectomy) was comparable to that of OG (with D2 lymphadenectomy). In another matched-case control study, which included patients with EGC and AGC, the short-term and long-term outcomes of 29 RG and
120 OG patients were compared (28). In the study that included patients who underwent distal and total gastrectomy, the RG group had a longer operation time (290 vs. 222 minutes); less blood loss (198 vs. $386 \mathrm{~mL}$ ) and shorter hospital stay (9 vs. 13 days). There was no significant difference in morbidity and mortality between the groups. There was no survival difference between both groups in a mean follow-up period of 25 months. This study concluded that RG was not only technically feasible, but also oncologically effective as compared to OG.

\section{Robotic gastrectomy versus Laparoscopic gastrectomy}

The results of the studies that compared short-term outcomes of RG and LG are presented in Table 2 (29-37). In the largest series (236 RG vs. 591 LG) among these studies, none of patients required open conversion (30). This comparative study demonstrates that RG group had better short-term outcomes and comparable oncologic outcomes compared to LG. Besides, the RG group had a significantly longer operation time while blood loss was less in the RG group. While the median hospital stay was five days in both groups $(61 \%$ of the patients in the RG group, and $49 \%$ of the patients in the LG group were discharged on day 5), the hospital stay in the RG group was longer due to two patients with complicated postoperative courses. No difference was observed between the groups in the number of retrieved lymph nodes. In a study that reported long-term survival of both EGC and AGC patients, 3-year overall survival rates were $85 \%$ and $78 \%$ for $L G$ and $R G$, respectively (29).

In the meta-analysis of nine studies that compared LG and RG for gastric cancer, RG group showed longer operation time (MD: $49 \mathrm{~min}$.), less blood loss (MD: $34 \mathrm{~mL}$ ), and shorter time to oral intake (MD: 0.28 days) (38). There was no significant difference in hospital stay, anastomotic leakage, morbidity, mortality, and conversion rates. Regarding the operative oncological outcomes, analysis of pooled data revealed that there was no significant difference between groups in terms of the number of retrieved lymph nodes and proximal resection margin. Authors concluded that in the absence of long-term follow-up data, it is difficult to evaluate the oncological efficacy of RG in terms of recurrence and survival.

\section{Robotic gastrectomy versus Laparoscopic gastrectomy versus Open gastrectomy}

In the first study comparing three approaches, the RG group had less blood loss compared to the OG group, and shorter hospital stay compared to the LG and OG groups (39). Postoperative morbidity and time to first flatus were comparable between the three groups. Longer operation time was determined as the only disadvantage of RG (127 min., 204 min., and 259 min. for OG, LG, and RG, respectively). Similar short-term outcomes were achieved in another study that compared the three methods (40). According to the study that evaluated the learning curve effect for RG, the operation time significantly decreased after the first 25 cases (115 min. less for operative time and $30 \mathrm{~min}$. less for docking time). In another study that evaluated the short-term outcomes of approximately $6000 \mathrm{pa}$ tients, overall complication and mortality rates were comparable between the three groups (41). However, postoperative 
ileus and intraabdominal fluid collection rates were higher in the OG group, while the rate of anastomosis leakage was higher in the LG and RG groups (leakage rate of groups: $1.1 \%$ in OG, $2.1 \%$ in LG, and 2.3 in RG). According to the authors, higher leakage rate may be associated with the differences in stapleline reinforcement or difficulty in considering the tension on the anastomosis owing to limited tactile feedback.

\section{Overview of the Literature}

It is difficult to reach a conclusion regarding the efficacy and safety of MI gastrectomy due to the lack of high-level evidence. The number of randomized studies that compare Ml gastrectomy and conventional open gastrectomy is low, and the majority of the studies are retrospective cohort series. However, the results of ongoing phase II/III studies in Korea and Japan will fulfill the shortcomings on this topic.

Considering the studies that have been published so far, almost all authors share the notion that LG and RG are safe, technically feasible, and oncologically effective methods. MI gastrectomy is an ideal alternative to open gastrectomy, especially for patients with EGC or for tumors that are located distally. Less blood loss, improved postoperative course, and earlier recovery are possible to achieve with $\mathrm{Ml}$ gastrectomy. On the other hand, longer operation time and increased costs (especially for RG) are the common concerns of MI gastrectomy.

In complex operations such as gastrectomy, the operation time is closely related to the surgeon's experience. Therefore, it is important to keep in mind the learning curve effect in most of the published studies. Following the increase of surgeon's experience on Ml gastrectomy, the operation times have significantly decreased in studies that were published recently and in studies that were carried out by experienced centers with high case volume.

A reduction in the cost of robotic surgery does not seem possible in the near future. However, with increasing volume of evidence, which will demonstrate potential benefits of RG compared to OG and LG, it is possible that the cost of RG will be covered by insurance systems in many countries. The Korean study (clinicaltrials.gov no: NCT01309256), which evaluates the cost analysis, learning curve effect, and postoperative life quality of RG will offer new insights.

Robotic gastrectomy offers several advantages to improve the surgical quality of lymphadenectomy for lymph nodes around major vessels and lymph nodes that are relatively difficult to dissect (lymph nodes 8a, 10, 11p, 11d, 12a for accurate lymph node dissection and spleen-preserving gastrectomy). In addition to well-established advantages of robotic surgery such as three-dimensional image, magnified view of anatomical structures, elimination of the mirror image effect, coaxial alignment of the eyes-hands-tool tip and tremor filtering, robotic systems also provide image-guided surgery concept. TilePro ${ }^{\mathrm{TM}}$ (da Vin$\mathrm{Ci}^{\circ}$; Intuitive Surgical, Sunnyvale, CA, USA) is a multi-input display mode of the robotic system that allows the surgeon to view additional images simultaneously as a picture-on-picture on the robotic console screen and assistant monitors. 3D recons- tructed images for anatomical details, intraoperative sonographic images or endoscopic images can also be integrated into the robotic console (42).

\section{CONCLUSION}

Minimally invasive gastrectomy for gastric cancer is a complex procedure, which can be performed safely with the expected advantages of minimally invasive surgery. While the advantages of laparoscopy are well established, some limitations of laparoscopic technique and complexity of the lymph node dissection with standard laparoscopic instruments have led surgeons to investigate robotic surgery as an alternative approach to gastric cancer. As surgeons become more skillful at robotic gastrectomy and the clinical and oncologic outcomes remain favorable, robotic surgery may offer a promising alternative to traditional open or conventional laparoscopic gastrectomy.

Peer-review: Evaluated by the Editorial Board of the journal.

Author Contributions: Concept - W.J.H., A.G.; Design - W.J.H., A.G.; Supervision - W.J.H., A.G.; Data Collection and/or Processing - A.G.; Analysis and/or Interpretation - W.J.H., A.G.; Literature Review - A.G.; Writer A.G.; Critical Review - W.J.H.

Conflict of Interest: No conflict of interest was declared by the authors.

Financial Disclosure: The authors declared that this study has received no financial support.

\section{REFERENCES}

1. Jayne DG, Guillou PJ, Thorpe H, Quirke P, Copeland J, Smith AM, et al. Randomized trial of laparoscopic-assisted resection of colorectal carcinoma: 3-year results of the UK MRC CLASICC Trial Group. J Clin Oncol 2007; 25: 3061-3068. [CrossRef]

2. Cadiere GB, Himpens J, Germay O, Izizaw R, Degueldre M, Vandromme J, et al. Feasibility of robotic laparoscopic surgery: 146 cases. World J Surg 2001; 25: 1467-1477.

3. Jeong O, Park YK. Clinicopathological features and surgical treatment of gastric cancer in South Korea: the results of 2009 nationwide survey on surgically treated gastric cancer patients. J Gastric Cancer 2011; 11: 69-77. [CrossRef]

4. Kitano S, Iso Y, Moriyama M, Sugimachi K. Laparoscopy-assisted Billroth I gastrectomy. Surg Laparosc Endosc 1994; 4: 146-148.

5. Kim YW, Yoon HM, Eom BW, Park JY. History of minimally invasive surgery for gastric cancer in Korea. J Gastric Cancer 2012; 12: 13-17. [CrossRef]

6. Hyung WJ, Woo Y, Noh SH. Robotic surgery for gastric cancer: a technical review. Journal of Robotic Surgery 2011; 5: 241-249. [CrossRef]

7. Japanese Gastric Cancer Association. Japanese Classification of Gastric Carcinoma - 2nd English Edition. Gastric Cancer 1998; 1: 10-24. [CrossRef]

8. Sano T, Aiko T. New Japanese classifications and treatment guidelines for gastric cancer: revision concepts and major revised points. Gastric Cancer 2011; 14: 97-100. [CrossRef]

9. Marano A, Hyung WJ. Robotic gastrectomy: the current state of the art. J Gastric Cancer 2012; 12: 63-72. [CrossRef]

10. Woo Y, Hyung WJ, Kim HI, Obama K, Son T, Noh SH. Minimizing hepatic trauma with a novel liver retraction method: a simple liver suspension using gauze suture. Surg Endosc 2011; 25: 3939-3945. [CrossRef]

11. Kim HI, Hyung WJ, Lee CR, Lim JS, An JY, Cheong JH, et al. Intraoperative portable abdominal radiograph for tumor localization: a simple and accurate method for laparoscopic gastrectomy. Surg Endosc 2011; 25: 958-963. [CrossRef] 
12. Kitano S, Shiraishi N, Fujii K, Yasuda K, Inomata M, Adachi Y. A randomized controlled trial comparing open vs laparoscopy-assisted distal gastrectomy for the treatment of early gastric cancer: An interim report. Surgery 2002; 131: 306-311. [CrossRef]

13. Fujii K, Sonoda K, Izumi K, Shiraishi N, Adachi Y, Kitano S. T lymphocyte subsets and Th1/Th2 balance after laparoscopyassisted distal gastrectomy. Surg Endosc 2003; 17: 1440-1444. [CrossRef]

14. Hayashi $H$, Ochiai $T$, Shimada $H$, Gunji $Y$. Prospective randomized study of open versus laparoscopy-assisted distal gastrectomy with extraperigastric lymph node dissection for early gastric cancer. Surg Endosc 2005; 19: 1172-1176. [CrossRef]

15. Lee $\mathrm{JH}, \mathrm{Han} \mathrm{HS}$, Lee $\mathrm{JH}$. A prospective randomized study comparing open vs laparoscopy-assisted distal gastrectomy in early gastric cancer: early results. Surg Endosc 2005; 19: 168-173. [CrossRef]

16. Huscher CG, Mingoli A, Sgarzini G, Sansonetti A, Di Paola M, Recher $A$, et al. Laparoscopic versus open subtotal gastrectomy for distal gastric cancer: five-year results of a randomized prospective trial. Ann Surg 2005; 241: 232-237. [CrossRef]

17. Kim YW, Baik YH, Yun YH, Nam BH, Kim DH, Choi IJ, et al. Improved quality of life outcomes after laparoscopy-assisted distal gastrectomy for early gastric cancer: results of a prospective randomized clinical trial. Ann Surg 2008; 248: 721-727. [CrossRef]

18. Kim HH, Hyung WJ, Cho GS, Kim MC, Han SU, Kim W, et al. Morbidity and mortality of laparoscopic gastrectomy versus open gastrectomy for gastric cancer: an interim report--a phase III multicenter, prospective, randomized Trial (KLASS Trial). Ann Surg 2010; 251: 417-420. [CrossRef]

19. Cai J, Wei D, Gao CF, Zhang CS, Zhang H, Zhao T. A prospective randomized study comparing open versus laparoscopy-assisted D2 radical gastrectomy in advanced gastric cancer. Dig Surg 2011; 28: 331-337. [CrossRef]

20. Chen XZ, Hu JK, Yang K, Wang L, Lu QC. Short-term evaluation of laparoscopy-assisted distal gastrectomy for predictive early gastric cancer: a meta-analysis of randomized controlled trials. Surg Laparosc Endosc Percutan Tech 2009; 19: 277-284. [CrossRef]

21. Kim YW, Yoon HM, Yun YH, Nam BH, Eom BW, Baik YH, et al. Longterm outcomes of laparoscopy-assisted distal gastrectomy for early gastric cancer: result of a randomized controlled trial (COACT 0301). Surg Endosc 2013; 27: 4267-4276. [CrossRef]

22. Katai H, Sasako M, Fukuda H, Nakamura K, Hiki N, Saka M, et al. Safety and feasibility of laparoscopy-assisted distal gastrectomy with suprapancreatic nodal dissection for clinical stage I gastric cancer: a multicenter phase II trial (JCOG 0703). Gastric Cancer 2010; 13: 238-244. [CrossRef]

23. Chen K, Xu XW, Mou YP, Pan Y, Zhou YC, Zhang RC, et al. Systematic review and meta-analysis of laparoscopic and open gastrectomy for advanced gastric cancer. World J Surg Oncol 2013; 11: 182. [CrossRef]

24. Zhao Y, Yu P, Hao Y, Qian F, Tang B, Shi Y, et al. Comparison of outcomes for laparoscopically assisted and open radical distal gastrectomy with lymphadenectomy for advanced gastric cancer. Surg Endosc 2011; 25: 2960-2966. [CrossRef]

25. Chen K, Xu XW, Zhang RC, Pan Y, Wu D, Mou YP. Systematic review and meta-analysis of laparoscopy-assisted and open total gastrectomy for gastric cancer. World J Gastroenterol 2013; 19: 5365-5376. [CrossRef]

26. Song J, Oh SJ, Kang WH, Hyung WJ, Choi SH, Noh SH. Robot-assisted gastrectomy with lymph node dissection for gastric cancer: lessons learned from an initial 100 consecutive procedures. Ann Surg 2009; 249: 927-932. [CrossRef]
27. Pernazza G, Gentile E, Felicioni L, Tumbiolo S, Giulianotti PC. Improved early survival after robotic gastrectomy in advanced gastric cancer. Surg Laparosc Endosc Percutan Tech 2006; 16: 286. [CrossRef]

28. Caruso S, Patriti A, Marrelli D, Ceccarelli G, Ceribelli C, Roviello F, et al. Open vs robot-assisted laparoscopic gastric resection with D2 lymph node dissection for adenocarcinoma: a case-control study. Int J Med Robot 2011; 7: 452-458. [CrossRef]

29. Pugliese R, Maggioni D, Sansonna F, Costanzi A, Ferrari GC, Di Lernia $S$, et al. Subtotal gastrectomy with $D 2$ dissection by minimally invasive surgery for distal adenocarcinoma of the stomach: results and 5-year survival. Surg Endosc 2010; 24: 2594-2602. [CrossRef]

30. Woo Y, Hyung WJ, Pak KH, Inaba K, Obama K, Choi SH, et al. Robotic gastrectomy as an oncologically sound alternative to laparoscopic resections for the treatment of early-stage gastric cancers. Arch Surg 2011; 146: 1086-1092. [CrossRef]

31. Eom BW, Yoon HM, Ryu KW, Lee JH, Cho SJ, Lee JY, et al. Comparison of surgical performance and short-term clinical outcomes between laparoscopic and robotic surgery in distal gastric cancer. Eur J Surg Oncol 2012; 38: 57-63. [CrossRef]

32. Uyama I, Kanaya S, Ishida Y, Inaba K, Suda K, Satoh S. Novel integrated robotic approach for suprapancreatic D2 nodal dissection for treating gastric cancer: technique and initial experience. World J Surg 2012; 36: 331-337. [CrossRef]

33. Yoon HM, Kim YW, Lee JH, Ryu KW, Eom BW, Park JY, et al. Robotassisted total gastrectomy is comparable with laparoscopically assisted total gastrectomy for early gastric cancer. Surg Endosc 2012; 26: 1377-1381. [CrossRef]

34. Kang BH, Xuan Y, Hur H, Ahn CW, Cho YK, Han SU. Comparison of surgical outcomes between robotic and laparoscopic gastrectomy for gastric cancer: The Learning curve of robotic surgery. J Gastric Cancer 2012; 12: 156-163. [CrossRef]

35. Park JY, Jo MJ, Nam BH, Kim Y, Eom BW, Yoon HM, et al. Surgical stress after robot-assisted distal gastrectomy and its economic implications. Br J Surg 2012; 99: 1554-1561. [CrossRef]

36. Hyun MH, Lee CH, Kwon YJ, Cho SI, Jang YJ, Kim DH, et al. Robot versus laparoscopic gastrectomy for cancer by an experienced surgeon: comparisons of surgery, complications, and surgical stress. Ann Surg Oncol 2013; 20: 1258-1265. [CrossRef]

37. Noshiro H, lkeda O, Urata M. Robotically-enhanced surgical anatomy enables surgeons to perform distal gastrectomy for gastric cancer using electric cautery devices alone. Surg Endosc 2013. [Epub ahead of print] [CrossRef]

38. Xiong J, Nunes QM, Tan C, Ke N, Chen Y, Hu W, et al. Comparison of short-term clinical outcomes between robotic and laparoscopic gastrectomy for gastric cancer: A meta-analysis of 2495 patients. J Laparoendosc Adv Surg Tech A 2013; 23: 965-976. [CrossRef]

39. Kim MC, Heo GU, Jung GJ. Robotic gastrectomy for gastric cancer: surgical techniques and clinical merits. Surg Endosc 2010; 24: 610-615. [CrossRef]

40. Huang KH, Lan YT, Fang WL, Chen JH, Lo SS, Hsieh MC, et al. Initial experience of robotic gastrectomy and comparison with open and laparoscopic gastrectomy for gastric cancer. J Gastrointest Surg 2012; 16: 1303-1310. [CrossRef]

41. Kim KM, An JY, Kim HI, Cheong JH, Hyung WJ, Noh SH. Major early complications following open, laparoscopic and robotic gastrectomy. Br J Surg 2012; 99: 1681-1687. [CrossRef]

42. Kim YM, Baek SE, Lim JS, Hyung WJ. Clinical application of imageenhanced minimally invasive robotic surgery for gastric cancer: a prospective observational study. J Gastrointest Surg 2013; 17: 304-312. [CrossRef] 